\title{
Levels of target activation predict antifibrotic responses to tyrosine kinase inhibitors
}

\author{
Britta Maurer, ${ }^{1}$ Alfiya Distler, ${ }^{2}$ Clara Dees, ${ }^{2}$ Korsa Khan, ${ }^{3}$ Christopher P Denton, ${ }^{3}$ \\ David Abraham, ${ }^{3}$ Renate E Gay, ${ }^{1}$ Beat A Michel, ${ }^{1}$ Steffen Gay, ${ }^{1}$ Jörg HW Distler, ${ }^{2}$ \\ Oliver Distler ${ }^{1}$
}

\begin{abstract}
Handling editor Tore K Kvien
- Additional material is

published online only. To view please visit the journal online (http://dx.doi.org/10.1136/ annrheumdis-2013-203729).

'Department of Rheumatology, University Hospital Zurich, Zurich, Switzerland

${ }^{2}$ Department of Internal Medicine 3, University of Erlangen-Nuremberg, Erlangen, Germany

${ }^{3}$ Centre for Rheumatology and Connective Tissue Diseases, UCL Medical School, Royal Free Campus, London, UK
\end{abstract}

\section{Correspondence to} Dr Oliver Distler, Department of Rheumatology, University Hospital Zurich, Gloriastrasse 25, Zurich 8091, Switzerland; oliver.distler@usz.ch

Received 5 April 2013 Revised 29 June 2013 Accepted 20 August 2013 Published Online First 7 September 2013

\begin{tabular}{|l|}
\hline To cite: Maurer B, \\
Distler A, Dees C, et al. Ann \\
Rheum Dis 2013;72: \\
2039-2046. \\
\hline
\end{tabular}

\section{ABSTRACT}

Objectives To assess whether the discrepancy between the strong antifibrotic effects of tyrosine kinase inhibitors (TKIs) in animal models and the inconsistent results in clinical studies might be related to the activation levels of drug targets.

Methods Skin sections of bleomycin, TSK1, Fra-2 transgenic mice, SSc patients and controls were analysed by histology and immunohistochemistry. Subgroups of mice were treated with the TKIs nilotinib or imatinib. Differences in the activation levels of the TKI targets p-PDGFR $\beta$ (platelet derived growth factor $\beta$ ) and $p-c-a b l$ were assessed.

Results In bleomycin and TSK 1 mice, expression of activated $p$-PDGFR $\beta$ (platelet derived growth factor receptor $\beta$ ) and $p$-c-abl was ubiquitous with strong upregulation compared with controls. Treatment with TKIs resulted in successful target inhibition and consequently reduced dermal fibrosis. In the Fra-2 model, the activation levels of p-PDGFR $\beta$ and $p-c-a b l$ were much lower than in the bleomycin and the TSK1 models. Accordingly, nilotinib did not prevent dermal fibrosis and target inhibition was unsuccessful. Notably, in skin biopsies of SSc patients, the mean activation levels of TKI targets were only moderate and in the majority of patients resembled those of the nonresponsive Fra-2 model.

Conclusions Animal models for proof-of-concept studies should be selected based on a similar activation level and expression pattern of drug targets as in human SSC.

\section{INTRODUCTION}

TGF $\beta$ and platelet derived growth factor (PDGF) are pro-fibrotic key molecules in systemic sclerosis (SSc). Because tyrosine kinase inhibitors (TKIs) such as imatinib, dasatinib and nilotinib efficiently block TGF $\beta$ and PDGF signalling by interfering with $\mathrm{c}-\mathrm{abl}$ and platelet derived growth factor receptor (PDGFR), they have been evaluated as potential antifibrotic agents in numerous animal models in which they consistently both prevented the onset of fibrosis and improved existing fibrosis in different organs. ${ }^{1-3}$

This led to clinical trials with TKIs as one of the first molecular targeted therapies in fibrotic diseases. Surprisingly, while open-label uncontrolled studies showed inconsistent results, ${ }^{4}$ randomised controlled trials failed to find significant antifibrotic effects. ${ }^{5} 6$ The reasons for these striking discrepancies between the convincing and consistent results in animal models and the overall disappointing effects in human fibrotic diseases have not been evaluated. Potential explanations include different activation levels and expression patterns of drug targets in animal models compared with patients.

Therefore, we assessed activation levels and expression patterns of the TKI targets c-abl and PDGFR in different fibrotic animal models and patients with SSc.

\section{METHODS}

Detailed information on methods is provided in the online supplementary data.

\section{Patients}

Skin biopsies were obtained from patients with diffuse $(n=10)$ and limited SSc $(n=28)$ (see online supplementary table S1) fulfilling the LeRoy criteria ${ }^{7}$ and healthy donors $(n=8)$.

\section{Animals}

Skin fibrosis was induced by bleomycin in C57/BL6 mice $(n=13) .{ }^{1}$ Control animals $(n=5)$ were treated with subcutaneous injections of $100 \mu \mathrm{L} 0.9 \% \mathrm{NaCl}$. Fra-2 tg mice $(n=12)^{89}$ were compared with wt littermates $(n=4)$.

Subgroups of bleomycin challenged $(n=9)$ and Fra-2 tg mice $(n=6)$ were treated with nilotinib at $2 \times 37.5 \mathrm{mg} / \mathrm{d}$ twice daily. ${ }^{1}$ Treatment control groups consisted of mice receiving $100 \mu \mathrm{L}$ of the vehicle 1-methyl-2-pyrrolidone/PEG300 by oral gavage twice daily ( $\mathrm{n}=4$ and 6 , respectively).

TSK1 mice $(n=8)^{10}$ were treated with imatinib at $150 \mathrm{mg} / \mathrm{kg} /$ day by intraperitoneal injections and compared with TSK1 $(\mathrm{n}=10)$ and $\mathrm{pa} / \mathrm{pa}$ control mice $(n=8)$ receiving $100 \mu \mathrm{L}$ of the solvent $\mathrm{NaCl}$ intraperitoneally. ${ }^{2}$

\section{Histology}

For the assessment of dermal thickness and extracellular matrix, sections were stained with $\mathrm{H} \& \mathrm{E}$ and Masson's trichrome staining.

\section{Immunohistochemistry}

Primary antibodies: mouse monoclonal: anti- $\alpha$ smooth muscle actin (SMA) (Sigma-Aldrich, Buchs, Switzerland), anti-SM22 $\alpha$ (abcam, Cambridge, UK) and anti-prolyl hydroxylase (acris, Nunningen, Switzerland); rabbit polyclonal: anti-von Willebrand factor, anti-p-PDGFR $\beta$ and anti-p-c-abl (all from abcam). 


\section{Analysis of skin sections}

Skin fibrosis was analysed in three consecutive skin sections at $\times 100$ magnification $^{9}$ by assessing dermal thickness and the number of myofibroblasts ( $\alpha$-SMA + ). Differences in the expression of dermal fibroblasts positively stained for TKI targets were determined by manual and automated counting (Image J software) in five randomly chosen high power field (HPF)/section at $\times 200$ magnification.

\section{Statistical analysis}

The Kolmogorov-Smirnov test was applied to test for normal distribution. Non-related, non-parametric parameters were analysed with the Mann-Whitney $\mathrm{U}$ test, and data are expressed as median ${ }_{(\mathrm{Q} 1, \mathrm{Q} 3)}$. Non-related parametric parameters were analysed with the unpaired $t$ test, and data are given as mean \pm SEM. $p$ Values $<0.05$ were considered statistically significant.

\section{RESULTS}

Response to TKIs in the bleomycin and the TSK1 models is reflected by the expression pattern and high activation status of PDGFRß and c-abl

In the bleomycin model, a frequently used model of chemically induced dermal fibrosis which reflects early inflammatory stages of SSc, the expression of p-PDGFR $\beta$ and p-c-abl was strongly

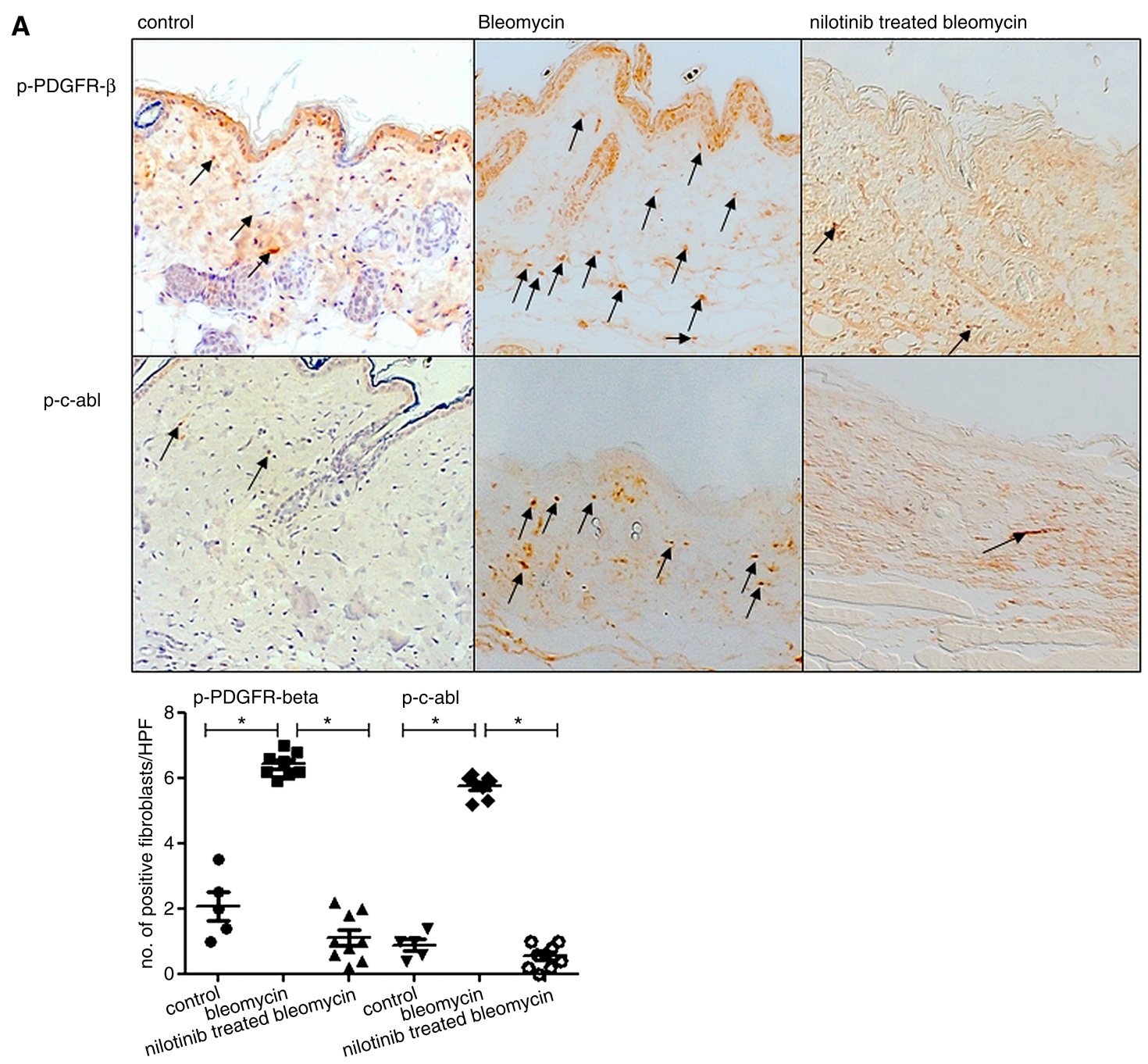

Figure 1 Response to nilotinib in the bleomycin and the TSK1 models is reflected by the expression pattern and activation status of PDGFR $\beta$ (platelet derived growth factor receptor $\beta$ ) and c-abl. (A) Nilotinib targets were ubiquitously expressed with predominance in dermal fibroblasts. Bleomycin challenged mice showed an increased expression of $p$-PDGFR $\beta$ and $p$-c-abl (brown staining, arrows) compared with controls, which was confirmed in the semiquantitative analysis ( $p$-PDGFR $\beta$ : mean \pm SEM $6.4 \pm 0.1$ vs $2.1 \pm 0.4$ positive cells/high power field (HPF), $p<0.0001 ; p$-c-abl: 5.8 \pm 0.1 vs $0.9 \pm 0.2$ positive cells/HPF, $p<0.0001$ ). Treatment with nilotinib led to significantly lower numbers of $p$-PDGFR and $p$-c-abl positive fibroblasts than in the bleomycin control group reaching levels as in mice without bleomycin ( $p$-PDGFR $\beta$ : mean $\pm S E M ~ 1.1 \pm 0.2, p<0.0001 ; p-c-a b l$ : $0.5 \pm 0.1$ positive cells/HPF, $p<0.0001$ ). (B) Compared with controls, skin fibrosis due to accumulation of extracellular matrix proteins (Masson's trichrome staining, green) as assessed by increase in dermal thickness (by mean \pm SEM $1.4 \pm 0.04$ fold, $p<0.0001$ ) and increased myofibroblast counts (by $\operatorname{median}_{(\mathrm{Q} 1, \mathrm{Q})} 2.5_{(1.6,3.4)}$ fold, $\left.\mathrm{p}=0.005\right)$ occurred after bleomycin challenge and was prevented in nilotinib treated mice with measures comparable with mice without bleomycin challenge (fold change of skin thickness by mean $\pm S E M 1.0 \pm 0.04, p=0.8$; fold change of myofibroblast counts by $\left.\operatorname{median}_{\left(\mathrm{Q}, Q_{3}\right)} 1_{(0.5,1)}, \mathrm{p}=0.09\right)$. Pictures are representative examples of saline treated control mice $(n=5)$, bleomycin mice $(n=13)$ and bleomycin+nilotinib treated mice $(n=9)$. (C) TSK1 mice showed an increased expression of $p$-PDGFR $\beta$ and $p$ - $c$-abl (brown staining, arrows) compared with $\mathrm{pa} / \mathrm{pa}$ mice, which was confirmed in the semiquantitative analysis ( $\mathrm{p}-\mathrm{PDGFR} \beta$ : mean $\pm \mathrm{SEM} 46.8 \pm 4.6$ vs $4.5 \pm 1.1 \mathrm{positive} \mathrm{cells/HPF,} \mathrm{p}<0.0001$; p-c-abl: $27.3 \pm 3.1$ vs $0.9 \pm 0.5$ positive cells/HPF, $p<0.0001)$. Treatment with imatinib led to significantly lower numbers of $p$-PDGFR and $p$-c-abl positive fibroblasts than in the TSK1 control group ( $p$-PDGFRß: mean \pm SEM 9.4 $\pm 3.7, p<0.0001 ; p-c-a b l: 18.3 \pm 2.2$ positive cells/HPF, $p=0.04$ ) and prevented skin fibrosis (Masson's trichrome staining, green). Pictures are representative examples of pa/pa mice $(n=8)$, control TSK1 mice $(n=10)$ and TSK1 mice treated with imatinib $(n=8)$. 
B

Skin thickness

control

bleomycin

nilotinib treated bleomycin
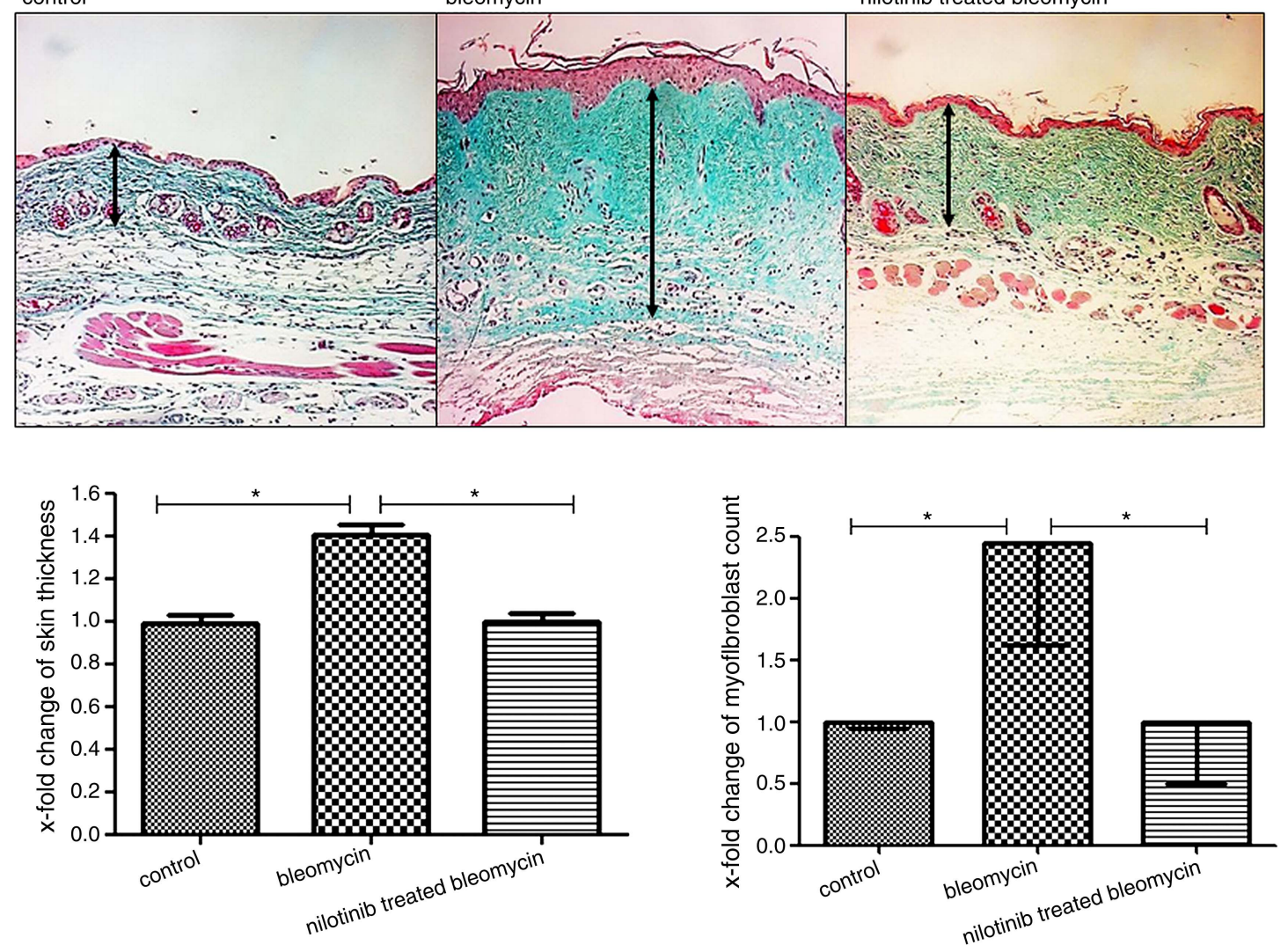

C
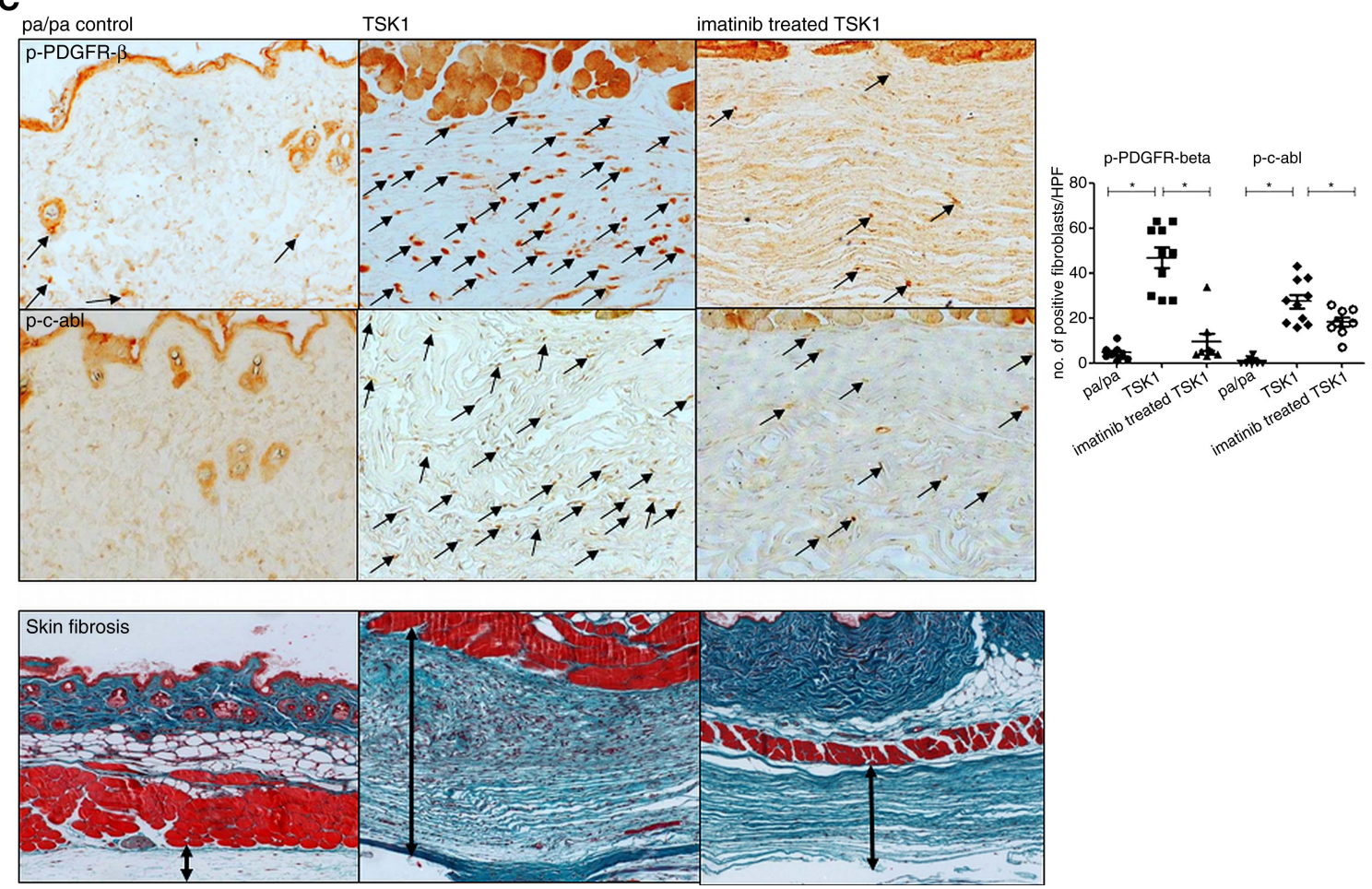

Figure 1 Continued. 
increased. Although the expression of activated PDGFR $\beta$ and c-abl was ubiquitous including vascular structures, it was most abundant in fibroblasts scattered throughout the dermis (figure 1A). Accordingly, dermal fibroblasts showed significantly more frequent activation of TKI targets in bleomycin mice compared with controls (figure 1A).

Skin fibrosis was assessed by skin thickness, and confirmed by Masson's trichrome staining and $\alpha$-SMA+ myofibroblasts counts. In all measures, skin fibrosis was significantly increased in bleomycin mice compared with control mice (figure 1B). Consistent with the high level of activation of TKI targets, nilotinib prevented fibrosis with skin thickness, Masson's trichrome staining and $\alpha$-SMA + myofibroblasts counts similar to controls without bleomycin (figure 1B).

In parallel with the prevention of skin fibrosis, the number of p-PDGFR and p-c-abl+ fibroblasts was significantly lower in nilotinib treated than in control bleomycin mice reaching levels as in mice without bleomycin (figure 1A). These data indicate successful target inhibition by nilotinib in the bleomycin model.

In TSK1 mice, a late-stage, non-inflammatory SSc model, the expression of TKI targets in hypodermal fibroblasts was strongly increased (figure 1C) compared with control pa/pa mice. Consistently, imatinib prevented skin fibrosis, which was paralleled by significantly reduced numbers of $p$-PDGFR and p-c-abl+ fibroblasts in imatinib treated compared with control TSK1 mice (figure 1C).

\section{Lack of antifibrotic effects in Fra-2 tg mice is mirrored by low activation status of the TKI targets PDGFRß and c-abl}

In contrast to the bleomycin model, in Fra-2 tg mice, a genetic model with both fibrosis and vasculopathy, the activation status of TKI targets (figure 2A) was much lower than in the
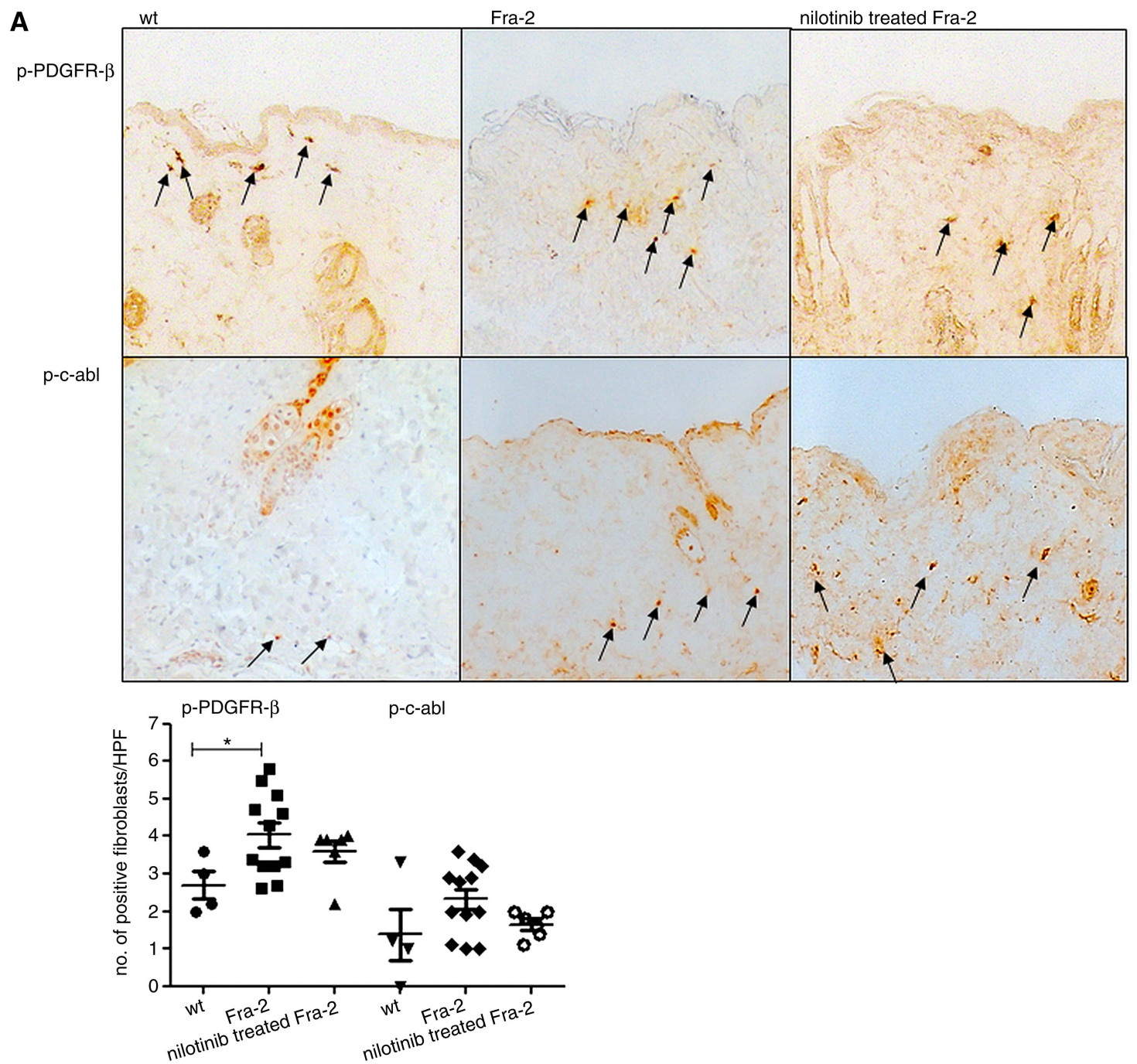

Figure 2 Response to nilotinib in the Fra-2 model is mirrored by the low expression pattern and activation status of PDGFR 3 and c-abl. (A) In Fra-2 tg mice, the activation status of tyrosine kinase inhibitor (TKI) targets was much lower than in the bleomycin model with dermal fibroblasts expressing $p$-PDGFR $\beta$ (brown staining arrows) (mean \pm SEM $4.0 \pm 0.3$ vs $2.7 \pm 0.4$ positive cells/high power field (HPF), $p=0.04)$ only slightly increased compared with wt mice and no differences for $p$-c-abl (brown staining, arrows) $(2.3 \pm 0.3$ vs $1.4 \pm 0.7$ positive cells/HPF, $p=0.1)$. Treatment with nilotinib had no effects on the activation status of the TKI targets $p$-PDGFR $\beta$ (mean \pm SEM $3.6 \pm 0.3$ positive cells/HPF, $p=0.4)$ and $p$-c-abl $(1.7 \pm 0.1$ positive cells/HPF, $p=0.1$ ). (B) In accordance with the expression pattern and the activation status of the TKI targets, nilotinib did not prevent the development of skin fibrosis (Masson's trichrome staining, green): Dermal thickness (change by mean \pm SEM $1.4 \pm 0.1$ vs $1.4 \pm 0.2$ fold, $p=0.7$ ) as well as myofibroblast counts (change by $\operatorname{median}_{(\mathrm{Q} 1, \mathrm{Q} 3)} 1^{1.5_{(1.5,1.6)}}$ vs $1_{(1.3,1.6)}$ fold, $\mathrm{p}=0.7$ ) did not differ between nilotinib treated Fra-2 mice and Fra-2 controls. Pictures are representative examples of wt $(n=4)$, Fra- 2 tg mice $(n=12)$, and nilotinib treated Fra- 2 tg mice $(n=6)$. 
B Skin thickness
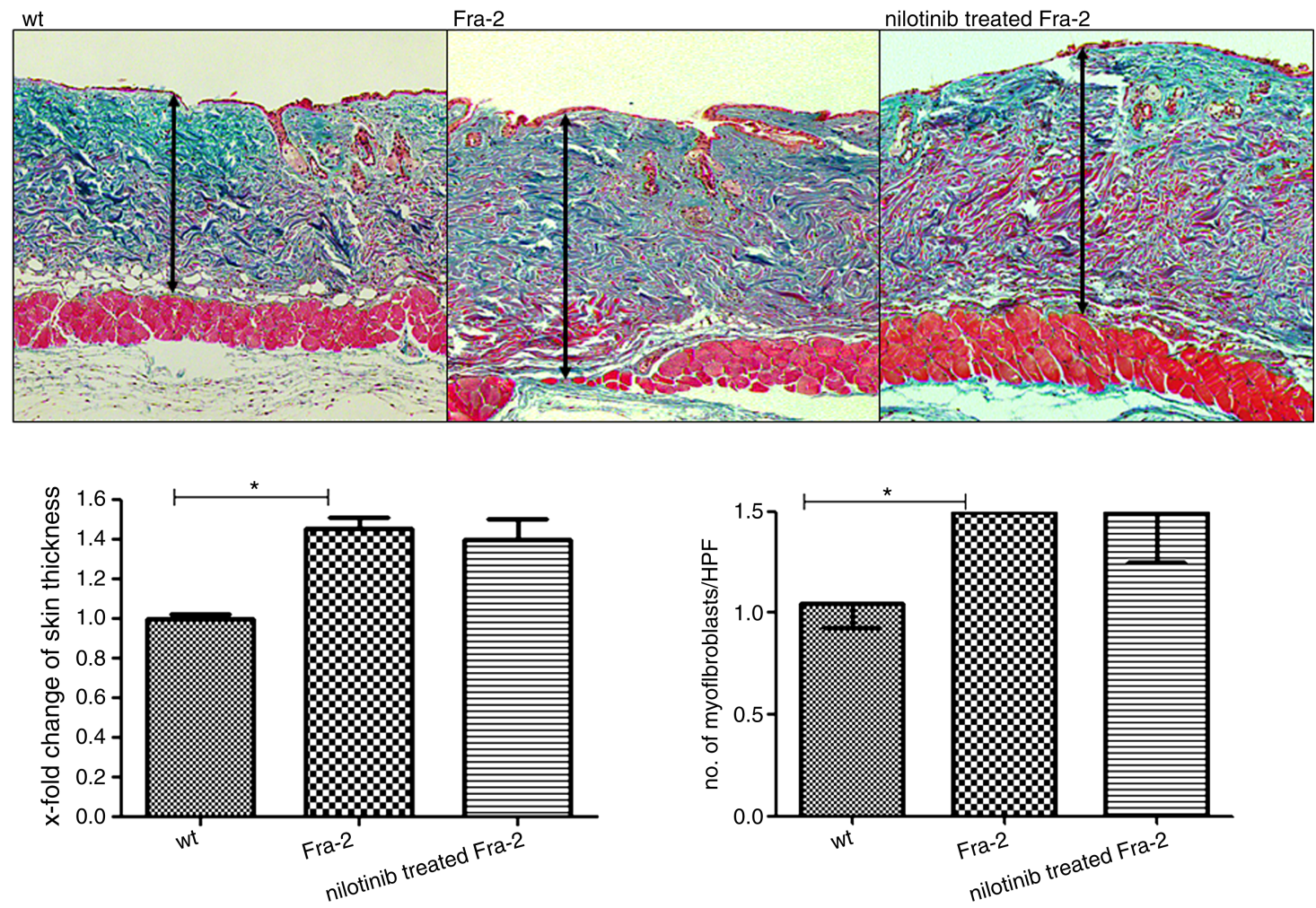

Figure 2 Continued.

bleomycin model (figure 1A). The number of $\mathrm{p}-\mathrm{c}-\mathrm{abl}+$ dermal fibroblasts was not different and the number of p-PDGFR $\beta+$ fibroblasts/cells was only slightly increased compared with wt controls.

Using the same measures as in the bleomycin model, Fra-2 tg mice developed significant skin fibrosis compared with wt controls (figure $2 \mathrm{~B}$ ) in agreement with previous reports. ${ }^{9}{ }^{11}$ However, consistent with the lack of TKI target activation, nilotinib did not prevent skin fibrosis since skin thickness, Masson's trichrome staining and $\alpha$-SMA+ myofibroblasts counts were not different between nilotinib treated and control animals (figure 2B). Accordingly, Fra- 2 tg mice showed similar numbers of p-PDGFR+ and $\mathrm{p}-\mathrm{c}-\mathrm{abl}+$ fibroblasts in nilotinib treated and control animals indicating lack of target inhibition (figure 2A).

These results suggest that the antifibrotic response could be predicted by the activation status and the expression pattern of the TKI targets in different animal models of SSc.

\section{Activation status and expression pattern of PDGFR $\beta$ and c-abl in human SSc}

Since in the animal experiments the activation status of TKI targets predicted the treatment response (figures 1 and 2), we next examined the dermal expression of p-PDGFR and p-c-abl in SSc (figure 3).

In patients with limited SSc, the number of p-PDGFR+ dermal fibroblasts did not differ from healthy controls (figure $3 \mathrm{~A}, \mathrm{~B})$, while in diffuse SSc patients, p-PDGFR $\beta+$ dermal fibroblasts were slightly increased compared with healthy controls (figure 3A,B). The number of $\mathrm{p}$-c-abl+ dermal fibroblasts did not differ from controls in all patients with SSc while they were slightly higher in diffuse than in limited SSc patients (figure 3A,B). Notably, while there was heterogeneity in SSc patients with some having levels as in the bleomycin model, the large majority of patients had low activation levels of both TKI targets with mean levels reflecting those seen in Fra- 2 tg mice.

The difference of human samples from the TKI-responsive bleomycin and TSK1 models was also reflected in the expression pattern of TKI targets. In SSc patients, the expression of activated PDGFR $\beta$ and c-abl was pronounced in vascular structures (figure 3C). Double staining for the respective cell markers revealed that in the skin of SSc patients, p-PDGFR $\beta$ and $\mathrm{p}-\mathrm{c}-\mathrm{abl}$ were expressed by vascular smooth muscle cells, endothelial cells and to a lesser extent in dermal fibroblasts. The immunostaining for $\mathrm{p}$-PDGFR $\beta$ and $\mathrm{p}$-c-abl in the sections was specific since substitution of the primary antibodies with the respective IgG resulted in absence of the respective staining.

\section{DISCUSSION}

Our study showed that the level of target activation and the expression pattern predicted the antifibrotic response to TKIs in three different animal models of SSc. Similarly, upregulation of p-PDGFR in the lung (not skin) of Fra-2 tg mice was recently shown to be accompanied by a significant reduction of pulmonary fibrosis upon treatment with nilotinib. ${ }^{12}$ In SSc patients, the activation status of TKI targets was only moderate, which might explain the overall disappointing results of clinical trials with TKIs in SSc.

Our findings have important implications for drug development in SSc: (1) The selection of animal models for preclinical proof-of-concept studies should be based-among other parameters ${ }^{13}$-on the activation level and expression pattern of drug targets. In this context, similar levels of target activation 

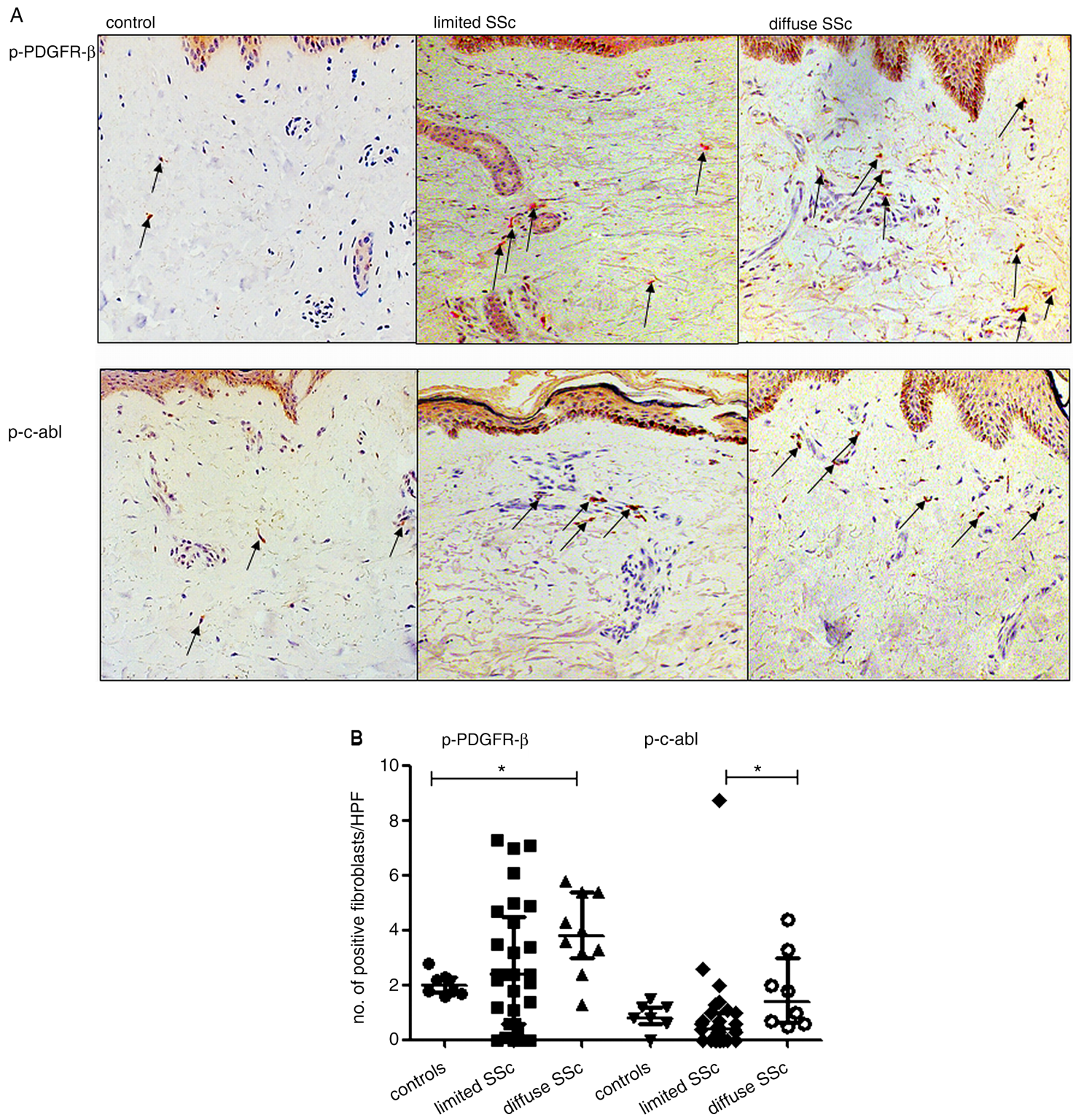

Figure 3 Activation status and expression pattern of PDGFR $\beta$ and $c-a b l$ in SSc. (A+B) In healthy controls, the expression of $p$-PDGFR $\beta$ (platelet derived growth factor receptor $\beta$ ) in dermal fibroblasts (red staining, arrows) was weak. While there was heterogeneity in all SSc patients, in patients with limited SSc, the number of p-PDGFR+ dermal fibroblasts (red staining, arrows) did not differ from healthy controls (median ${ }_{(\mathrm{Q} 1, Q 3)}$ $2.4_{(1,5)}$ vs $\left.2.0_{(2,2)}, p=0.7\right)$. In diffuse SSC patients, the activation status of PDGFR $\beta$ in dermal fibroblasts (red staining, arrows) was slightly increased compared with healthy controls $\left(3.8_{(3,5)}\right.$ positive cells/high power field (HPF), $\left.p=0.01\right)$ but not with patients with limited disease $\left(2.4_{(1,5)}\right.$ positive cells/HPF, $p=0.1$ ). The activation status of $c$-abl in dermal fibroblasts in patients with limited and diffuse SSc (brown staining, arrows) did not differ from controls $\left(0.4_{(0,1)}\right.$ and $1.4_{(1,3)}$ vs $0.8_{(1,1)}$ positive cells/HPF, $p=0.22$ and $p=0.4$, respectively). (C) In SSc patients, the expression of activated PDGFR $\beta$ and $c$-abl was pronounced in vascular structures. Double staining for the respective cell markers revealed that in the skin of SSc patients, p-PDGFR $\beta$ (brown) and p-c-abl (brown) were expressed by vascular smooth muscle cells (SM22 $\alpha+$, purple), endothelial cells (von Willebrand factor+, purple) and to a lesser extent in dermal fibroblasts (prolyl hydroxylase+, greenish). Representative sections of healthy controls $(n=8)$, patients with limited SSC $(n=28)$ and with diffuse SSC $(n=10)$ are presented.

in humans and animal models are crucial to delineate potential treatment responses in human SSc. (2) Our data underline the potential importance of personalised medicine in targeted therapies of SSc. Activation levels of TKI targets were highly heterogeneous in SSc patients. While most patients showed low activation levels, in some the activation status of TKI targets was as high as in the strongly responsive bleomycin model. These data together with recent gene array studies ${ }^{14} 15$ suggest that the analysis of target activation levels could identify patients more likely to benefit from TKI treatment for fibrosis.
(3) Our data also suggest that TKI targets might play a role in the vascular manifestations of SSc due to their pronounced expression pattern in vascular structures of SSc patients. Recently, p-PDGFR $\beta$ has been suggested as an important molecule in the pathogenesis of pulmonary arterial hypertension, ${ }^{16}$ and nilotinib prevented the development of proliferative vasculopathy in Fra-2 tg mice. ${ }^{12}$ In addition, imatinib improved exercise capacity and haemodynamics in patients with advanced pulmonal arterial hypertension (PAH) in a recent randomised, double-blind, placebo-controlled trial. ${ }^{17}$ 
C
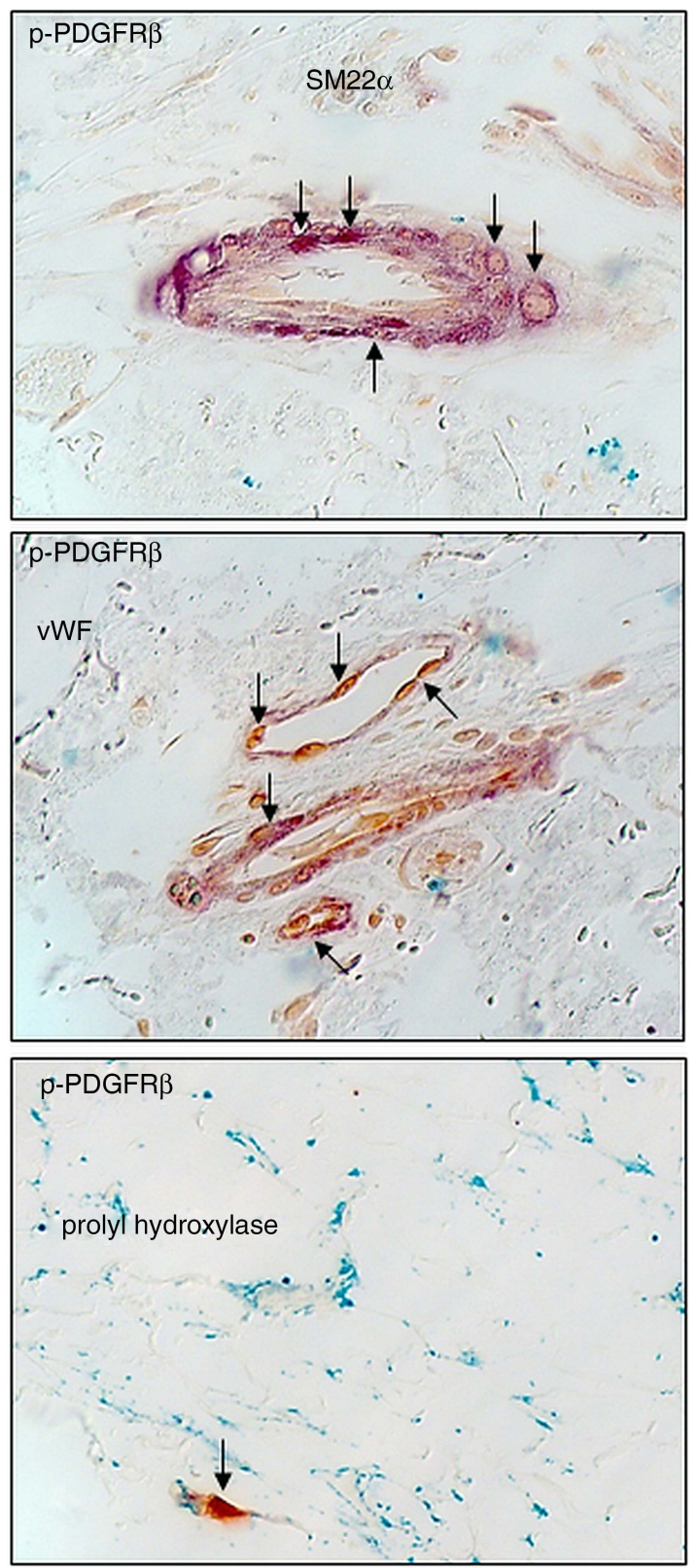

Figure 3 Continued.

Acknowledgements The authors thank Maria Comazzi for the excellent technical support.

Contributors BM, OD: Conception and design of the study, analysis and interpretation of data, drafting the article. $A D, C D$ : Participation in animal experiments. $A D, C D, K K, C P D, D A, R E G, S G, B A M$ : Analysis and interpretation of data, critical revision of the manuscript. JHWD: Conception and design of the study, analysis and interpretation of data, critical revision of the manuscript. All authors have given their final approval of the manuscript to be published as presented. BM and OD accept full responsibility for the work and/or the conduct of the study, had access to the data, and controlled the decision to publish.

Competing interests JHWD has consultancy relationships and/or has received research funding from Boehringer Ingelheim, Celgene, Bayer Pharma, Actelion, Pfizer, Ergonex, BMS, JB Therapeutics, Anaphore, Inc, Sanofi-Aventis, Novartis, Array Biopharma and Active Biotec in the area of potential treatments of scleroderma and is stock owner of $4 \mathrm{D}$ Science. OD has/had consultancy relationship and/or has received research funding in the area of systemic sclerosis and related conditions from Actelion, Pfizer, Ergonex, BMS, Sanofi-Aventis, United BioSource Corporation, Roche/Genentech, medac, Biovitrium, Boehringer Ingelheim Pharma, Novartis, 4D Science, Active Biotec, Bayer-Schering Sinoxa, Serodapharm and EpiPharm. CPD has
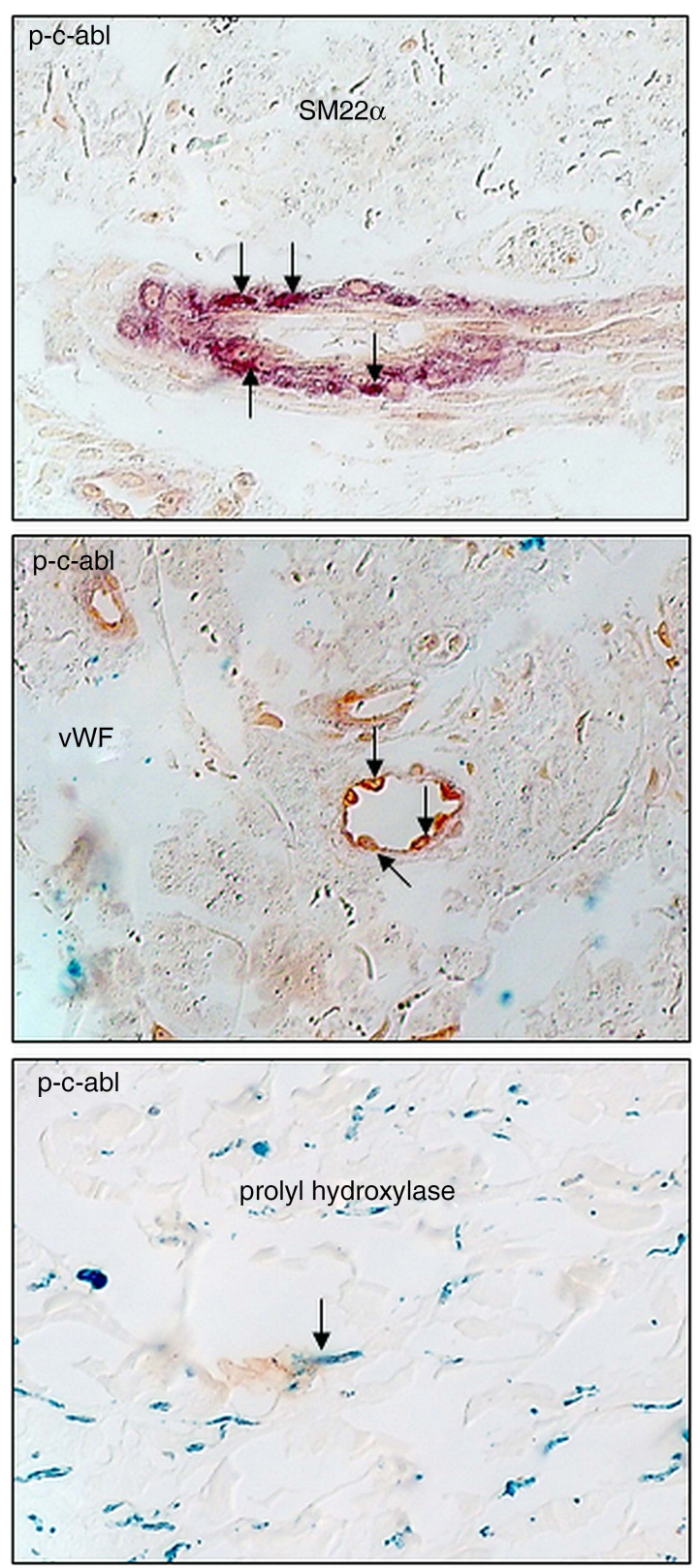

been a consultant to, or received honoraria from, Actelion, Pfizer, Ergonex, Sanofi-Aventis, United BioSource Corporation, Roche/Genentech, Biovitrium, Boehringer Ingelheim Pharma, Novartis and Digna pharmaceuticals. All authors were supported by their respective institutions. The real or perceived potential conflicts listed above are accurately stated.

Patient consent Obtained and is stated in the online data supplement.

Ethics approval Obtained and is stated in the online data supplement.

Provenance and peer review Not commissioned; externally peer reviewed.

\section{REFERENCES}

1 Akhmetshina A, Dees C, Pileckyte M, et al. Dual inhibition of c-abl and PDGF receptor signaling by dasatinib and nilotinib for the treatment of dermal fibrosis. FASEB J 2008;22:2214-22.

2 Akhmetshina $A$, Venalis $P$, Dees $C$, et al. Treatment with imatinib prevents fibrosis in different preclinical models of systemic sclerosis and induces regression of established fibrosis. Arthritis Rheum 2009;60:219-24. 
3 Daniels $C E$, Wilkes $M$, Edens $M$, et al. Imatinib mesylate inhibits the profibrogenic activity of TGF-beta and prevents bleomycin-mediated lung fibrosis. I Clin Invest 2004;114:1308-16.

4 Beyer C, Distler O, Distler JH. Innovative antifibrotic therapies in systemic sclerosis. Curr Opin Rheumatol 2012:24:274-80.

5 Pope J, McBain D, Petrlich L, et al. Imatinib in active diffuse cutaneous systemic sclerosis: Results of a six-month, randomized, double-blind, placebocontrolled, proof-of-concept pilot study at a single center. Arthritis Rheum 2011;63:3547-51.

6 Daniels CE, Lasky JA, Limper AH, et al. Imatinib treatment for idiopathic pulmonary fibrosis: Randomized placebo-controlled trial results. Am J Respir Crit Care Med 2010;181:604-10.

7 LeRoy EC, Black C, Fleischmajer R, et al. Scleroderma (systemic sclerosis): classification, subsets and pathogenesis. J Rheumatol 1988;15:202-5.

8 Eferl $\mathrm{R}$, Hasselblatt $\mathrm{P}$, Rath $\mathrm{M}$, et al. Development of pulmonary fibrosis through a pathway involving the transcription factor Fra-2/AP-1. Proc Natl Acad Sci USA 2008; 105:10525-30

9 Maurer B, Busch N, Jungel A, et al. Transcription factor fos-related antigen-2 induces progressive peripheral vasculopathy in mice closely resembling human systemic sclerosis. Circulation 2009;120:2367-76.
10 Green MC, Sweet HO, Bunker LE. Tight-skin, a new mutation of the mouse causing excessive growth of connective tissue and skeleton. Am J Patho/ 1976;82:493-512.

11 Reich N, Maurer B, Akhmetshina A, et al. The transcription factor Fra-2 regulates the production of extracellular matrix in systemic sclerosis. Arthritis Rheum 2010;62:280-90.

12 Maurer B, Reich N, Juengel A, et al. Fra-2 transgenic mice as a novel model of pulmonary hypertension associated with systemic sclerosis. Ann Rheum Dis 2012;71:1382-7.

13 Distler JH, Distler 0. Criteria to select molecular targets for anti-fibrotic therapy. Rheumatology (Oxford) 2008;47(Suppl 5):v12-13.

14 Chung L, Fiorentino DF, Benbarak MJ, et al. Molecular framework for response to imatinib mesylate in systemic sclerosis. Arthritis Rheum 2009;60:584-91.

15 Sargent JL, Milano A, Bhattacharyya S, et al. A TGFbeta-responsive gene signature is associated with a subset of diffuse scleroderma with increased disease severity. J Invest Dermatol 2010:130:694-705.

16 Perros F, Montani D, Dorfmuller $\mathrm{P}$, et al. Platelet-derived growth factor expression and function in idiopathic pulmonary arterial hypertension. Am J Respir Crit Care Med 2008; 178:81-8.

17 Hoeper MM, Barst RJ, Bourge RC, et al. Imatinib Mesylate as Add-on Therapy for Pulmonary Arterial Hypertension: Results of the Randomized IMPRES Study. Circulation 2013;127:1128-38. 


\section{$\triangle R D$ Levels of target activation predict antifibrotic responses to tyrosine kinase inhibitors}

Britta Maurer, Alfiya Distler, Clara Dees, Korsa Khan, Christopher P

Denton, David Abraham, Renate E Gay, Beat A Michel, Steffen Gay, Jörg HW Distler and Oliver Distler

Ann Rheum Dis 2013 72: 2039-2046 originally published online September 7, 2013

doi: 10.1136/annrheumdis-2013-203729

Updated information and services can be found at:

http://ard.bmj.com/content/72/12/2039

These include:

Supplementary Material

References

Email alerting service
Supplementary material can be found at:

http://ard.bmj.com/content/suppl/2013/09/07/annrheumdis-2013-2037 29.DC1.html

This article cites 17 articles, 6 of which you can access for free at: http://ard.bmj.com/content/72/12/2039\#BIBL

Receive free email alerts when new articles cite this article. Sign up in the box at the top right corner of the online article.

$\begin{array}{cc}\text { Topic } & \text { Articles on similar topics can be found in the following collections } \\ \text { Collections } & \text { Pathology (444) } \\ & \text { Clinical diagnostic tests (1282) } \\ & \text { Genetics (968) } \\ \text { Immunology (including allergy) (5144) } & \text { Radiology (1113) } \\ & \text { Surgical diagnostic tests (431) }\end{array}$

\section{Notes}

To request permissions go to:

http://group.bmj.com/group/rights-licensing/permissions

To order reprints go to:

http://journals.bmj.com/cgi/reprintform

To subscribe to BMJ go to:

http://group.bmj.com/subscribe/ 